Letrônica, Porto Alegre, v. 7, n. 1, p. 198-224, jan./jun., 2014

\title{
A INFLUÊNCIA DA COESÃO E DA COERÊNCIA NO PROCESSAMENTO CORREFERENCIAL DE PRONOMES E NOMES REPETIDOS EM PORTUGUÊS BRASILEIRO ${ }^{1}$
}

\author{
THE INFLUENCE OF COHESION AND COHERENCE IN COREFERENTIAL PROCESSING \\ OF PRONOUNS AND REPEATED NAMES IN BRAZILIAN PORTUGUESE
}

\author{
Antonia Simões* \\ Márcio Martins Leitão**
}

\begin{abstract}
Resumo: Esta pesquisa investigou a influência da coesão e da coerência no processamento correferencial de pronomes e nomes repetidos em português brasileiro. Estudos afirmam que pronomes são mais dependentes do contexto linguístico do que os nomes repetidos (GARROD et al., 1994) e que os conectivos facilitam o processamento sentencial (SANDERS; NOORDMAN, 2000). Dois experimentos utilizando a técnica de leitura automonitorada foram realizados para observarmos o processamento da retomada anafórica com pronomes e nomes repetidos a partir da manipulação de recursos de coesão (conectivos) e da coerência das sentenças experimentais. 0 processamento pronominal, observado no experimento 1 , não foi afetado por questões de incongruência ou pela existência de conectivos. Sentenças do experimento 2 tiveram diferenças significativas no tempo de leitura, a partir da leitura da retomada anafórica com nome repetido. Observamos que o processamento de elementos linguísticos incongruentes e retomada anafórica com nomes repetidos é mais custoso para a memória de trabalho quando comparados com o processamento de incongruências e anáfora pronominal. A hipótese da carga informacional (ALMOR, 1999) pode explicar os resultados encontrados nos experimentos com pronomes e nomes repetidos.
\end{abstract}

Palavras-chave: Processamento correferencial; Pronome; Nome Repetido; Coesão; Coerência.

Abstract: The present study investigated the influence of cohesion and coherence during
coreferential processing. Studies show that pronouns are more dependent on the linguistic
context than repeated names (GARROD et al., 1994), and that connectives facilitate sentence
processing (SANDERS; NOORDMAN, 2000). Using the technique of self-paced reading, we
carried out two experiments to investigate anaphoric processing with pronouns and

1 Trabalho realizado com auxílio do CNPq (Projeto Universal 14/2012 - Processo N. 486748/2012-0 e Produtividade e Pesquisa - PQ/2012 - Processo N. 307558/2012-6).

* Possui graduação em Letras pela Universidade Federal da Paraíba - UFPB (2011), mestrado em Linguística pela UFPB (2014). É membro do Laboratório de Processamento Linguístico (LAPROL), tendo publicado artigo a respeito de experimento também investigando o processamento anafórico (http://www.ufjf.br/revistaveredas/files/2011/05/ARTIGO-191.pdf).

${ }^{* *}$ Possui graduação em português - Literaturas pela Universidade Federal do Rio de Janeiro - UFRJ (1997), mestrado em Linguística pela UFRJ (2001) e doutorado em Linguística pela UFRJ (2005). Atualmente é professor adjunto da UFPB e coordena o LAPROL (Laboratório de Processamento Linguístico). Publicou diversos trabalhos investigando o processamento correferencial, como, por exemplo: http://www.ufjf.br/revistaveredas /files/2009/12/artigo04.pdf. 
repeated names. We manipulated cohesion resources (connectives) and coherence of experimental sentences. The results show that, in experiment 1 , issues of incongruity or the presence of connectives did not affect pronoun processing. In experiment 2 , there were significant differences in reading times for reading the anaphoric resumption with repeated names. The processing of incongruous elements and linguistic anaphoric resumption with repeated names is more costly for a reader's working memory when compared with the processing of inconsistencies and pronominal anaphora. The informational load hypothesis (ALMOR, 1999) may explain the results from experiments with pronouns and repeated names.

Keywords: Coreferential processing; Pronoun; Repeated Name; Cohesion; Coherence.

\section{Introdução}

Em um processo comunicativo, o produtor de uma sequência linguística faz uso de elementos que, quando relacionados, dão pistas ao leitor/ouvinte para se chegar à compreensão sobre o que foi lido/ouvido. Temos como exemplo desses elementos linguísticos os pronomes, quando fazem referência a algo citado anteriormente num texto. Podemos também citar os conectivos, como as conjunções. Os recursos linguísticos formadores de uma sequência textual, chamados elementos de coesão, contribuem para que uma sequência linguística tenha sentido. São eles que costuram o produto final de um processo comunicativo: o texto.

Os recursos de coesão são utilizados na produção e na compreensão dos usuários da língua e, por esse motivo, interessam às áreas relacionadas aos estudos sobre a linguagem. Ocupamo-nos especificamente neste artigo com a área de conhecimento linguístico que investiga a produção e a compreensão da linguagem humana através de experimentos científicos: a Psicolinguística. No âmbito da psicolinguística experimental, portanto, esta pesquisa tem como objetivo principal investigar a influência da coesão e da coerência no processamento correferencial de pronomes e nomes repetidos em português brasileiro.

A ideia inicial da pesquisa surgiu a partir de uma informação contida em pesquisa realizada por Garrod et al. (1994). Há, na pesquisa citada, uma afirmação sobre a dependência do pronome relacionada ao contexto linguístico. Todavia, essa dependência contextual, exposta na pesquisa retromencionada, não é verificada no processamento dos nomes repetidos em função anafórica² ${ }^{2}$ Observamos, no mesmo artigo, a inexistência

\footnotetext{
2 Os termos "anáfora" e/ou "retomada anafórica" estão sendo usados neste artigo para descrever qualquer expressão que estabeleça correferência com um antecedente, como pronomes lexicais (por exemplo: ele
} 
de um conceito explícito a respeito do contexto linguístico. Sobre contexto linguístico, a partir das afirmações contidas no artigo, chegamos à conclusão de que está relacionado à necessidade, quando do encontro de uma anáfora, de voltar ao que foi dito/lido (contexto anterior) para solucionar esse tipo de recurso linguístico.

Para a realização desta pesquisa, caracterizamos o contexto linguístico observado da seguinte maneira: quando pensamos no movimento de retorno desencadeado pela leitura de uma anáfora, não nos resumimos à localidade do antecedente da retomada. Isso significa que observamos se a manipulação dos recursos de coesão e da coerência no contexto em que está inserido o antecedente afeta a resolução da retomada anafórica com pronomes e nomes repetidos.

Se os pronomes fossem mais dependentes do contexto linguístico, esperávamos encontrar diferentes tempos de leitura, nesse tipo de retomada anafórica, a depender das sentenças (congruentes ou incongruentes) antecedendo os pronomes. A resolução dos nomes repetidos, ao contrário, não sofreria qualquer tipo de influência de manipulação da coerência das sentenças antecedendo esse tipo de retomada por não dependerem, num primeiro momento, do contexto linguístico anterior.

Além da coerência textual, resolvemos utilizar recursos linguísticos conectivos nas sentenças dos experimentos realizados a fim de verificar aspectos mais pontuais referentes aos recursos de coesão. Os resultados encontrados, a partir de tais manipulações sentencias, proporcionaram reflexões a respeito da resolução anafórica a partir da influência da constituição sintática e semântica da sentença que antecede a retomada anafórica e, também, da existência dos elementos linguísticos de coesão como recursos fundamentadores para a obtenção da coerência textual.

\section{Contribuições da Linguística Textual ao estudo psicolinguístico}

O presente estudo objetivou verificar a influência dos recursos de coesão e da coerência no processamento de expressões anafóricas com pronomes e nomes repetidos. Recorremos à Linguística Textual para caracterizar com maior precisão os fatores manipulados nas sentenças experimentais, pois essa área de estudo da

ou ela). 0 uso do termo "anáfora" (em inglês, anaphora) é diferente do uso empregado pela gramática gerativa em que esse termo (em inglês, anaphor) faz referência, especificamente, aos reflexivos e aos recíprocos. 
linguagem investiga a coesão e a coerência como elementos fundamentadores do texto, inter-relacionando-se, dessa forma, com nossa pesquisa psicolinguística.

A Linguística Textual, surgida na década de 60, tem como objeto de estudo o texto. Este requer o acontecimento do sentido para quem o ouve/lể $\hat{e}^{3}$ A coerência está ligada a esse sentido, a essa percepção de que o que se está lendo ou escutando é compreensível. Essa percepção de sentido é obtida por parte do leitor/ouvinte a partir dos elementos linguísticos que compõem um texto. Esses elementos, numa sequência linguística textual, têm a propriedade de se relacionarem uns com os outros de maneira a formarem um todo coerente. Essa relação existente entre os elementos linguísticos compositores de um texto é obtida através dos recursos de coesão.

Os elementos fundadores de um texto, ou melhor, os requisitos para que uma passagem linguística seja considerada um texto são: a coesão e a coerência (KOCH; FÁVERO, 2012). A existência da coerência está relacionada a processos envolvendo vários fatores, a saber: conhecimento linguístico, conhecimento de mundo, conhecimento partilhado, inferências, fatores pragmáticos, situacionalidade, intencionalidade e aceitabilidade, informatividade, focalização, intertextualidade e relevância (KOCH; TRAVAGLIA, 2007). A citação a esses fatores serve para reforçar a obtenção da coerência como um processo capaz de provocar uma situação comunicativa entre usuários da língua e texto. A coerência, portanto, é estabelecida por uma série de fatores no qual o conhecimento linguístico é um deles.

Processo permeado de diversos fatores, o acontecimento do sentido se dá de maneira global, mas seu desenvolvimento pode ser localmente manifestado através de elementos linguísticos. Estes quando são relacionados uns aos outros de maneira harmônica manifestam a coerência textual. São os recursos de coesão, portanto, os responsáveis por manter essa relação entre os elementos linguísticos. É a partir deles que conseguimos chegar ao sentido do texto. Vejamos um exemplo:

(1) Ana foi ao mercado. Ela comprou muitos pães.

(2) Léo encontrou as camisas dentro da mala. Léo acabou de fazer uma viagem.

\footnotetext{
${ }^{3}$ Segundo Cançado (2012, p. 94), a definição de sentido é uma tarefa abstrata: “[...] Quando alguém entende completamente o que o outro diz, é perfeitamente razoável admitir que essa pessoa captou o sentido da expressão que ela ouviu". Assumimos neste trabalho, portanto, que a existência do texto está associada à percepção do leitor/ouvinte de que o que foi lido/ouvido é possível de ser entendido.
} 
A sentença (1) é marcada por dois momentos explicitados em duas orações. No segundo momento, para descobrirmos quem é a pessoa compradora de muitos pães só temos, nessa parte da sentença, informações de número e gênero. Assim, voltamos ao início da sentença para encontrarmos a solução para o pronome ela que será, nesse caso, o elemento linguístico Ana. Este combina com as informações de número e gênero fornecidas pelo elemento linguístico pronominal.

Na sentença (2), o elemento linguístico Léo, localizado na segunda parte da sentença, é o mesmo Léo da primeira parte. Essas considerações, óbvias, servem para mostrar que o pronome e o nome repetido, nas sentenças (1) e (2), precisaram de outros elementos linguísticos para serem interpretados. Duas expressões linguísticas são consideradas correferenciais quando se referem a um mesmo elemento (GORDON; HENDRICK, 1998). O pronome ela, na sentença (1), por exemplo, está estabelecendo uma relação de identidade referencial com o elemento linguístico Ana. Esta relação, portanto, pode ser considerada correferencial.

Percebemos, nos exemplos, a existência de certos elementos linguísticos fazendo remissão a outro elemento textual. 0 elemento que faz a remissão é chamado de forma referencial (no exemplo 1, o pronome ela) e o elemento a quem se refere é chamado de elemento de referência ou referente textual (no exemplo 1, o substantivo Ana). Esse tipo de relação é chamada de coesão referencial (KOCH, 1994).

Além de relações referenciais entre termos, representadas pela coesão referencial, existe também a coesão sequencial. Neste caso, elementos linguísticos conectivos ligam partes de sentenças. As conjunções, por exemplo, ao conectarem partes de uma sequência linguística acabam por relacionar conteúdos ${ }^{4}$. Quando encontramos uma conjunção, não temos uma instrução de procura, como acontece quando do encontro de um pronome, mas de relacionar o que foi dito/lido com aquilo que virá adiante no texto (HALLIDAY; HASAN, 1976). Por exemplo:

(3) Bia estudou bastante, porém não passou na prova.

\footnotetext{
4 É interessante percebemos o papel ou instrução contida nas conjunções porque elas também são articuladores responsáveis por encadeamento por conexão. Dessa forma, os elementos linguísticos utilizados nas sentenças experimentais com a função de conectar as orações também podem enquadrar-se nas características das conjunções. Expressões como por isso e portanto, utilizadas nas sentenças experimentais do presente trabalho, dão instrução de conexão para o leitor/ouvinte do texto.
} 
A partir da leitura da conjunção porém, o leitor sabe que os próximos elementos linguísticos a serem lidos terão uma relação de adversidade, ou oposição, com os elementos linguísticos localizados antes da conjunção. Essa relação de adversidade, apesar de estruturalmente localizada, manifesta uma instrução de sentido da sentença como um todo.

Através dos exemplos, quando utilizamos recursos linguísticos (como pronomes e conectivos) dispostos numa estrutura possível da língua, percebemos como acontece a coerência sintática. Esses elementos linguísticos, representados pelos recursos de coesão, estão relacionados harmonicamente em seus sentidos e por isso expressam a coerência semântica de um texto. A coerência semântica, portanto, "refere-se às relações de sentido entre as estruturas - palavras ou expressões presentes no texto" (KOCH; ELIAS, 2012, p. 196). A legibilidade do texto exige, portanto, a relação harmônica entre coesão e coerência.

Verificamos as relações de coesão e a coerência no âmbito dos estudos sobre o texto com o objetivo de compreender e caracterizar os fatores manipulados nas sentenças experimentais. É interessante reportarmos estudos psicolinguísticos envolvendo os fatores linguísticos observados até agora: pronomes e nomes repetidos em função anafórica; congruência/incongruência em sentenças; recursos de coesão sequencial. Do enquadramento conceitual fornecido pela Linguística Textual partiremos para o relato de experimentos que verificaram como os usuários da língua processam o texto online, ou seja, no momento exato da leitura.

\section{Estudos psicolinguísticos envolvendo coesão e coerência}

Os tipos de retomadas anafóricas, mais precisamente pronomes e nomes repetidos, foram um dos elementos linguísticos investigados por Garrod et al. (1994) através de experimentos utilizando a técnica de rastreamento ocular5.

Os pronomes são lexicalmente transparentes, nesse sentido, seu conteúdo lexical é mínimo e por isso sua interpretação é limitada quando utilizamos somente seu próprio

\footnotetext{
${ }^{5} \mathrm{O}$ eyetracking ou rastreador ocular é um equipamento capaz de monitorar o movimento ocular durante uma tarefa experimental como a leitura de um texto, por exemplo.
} 
conteúdo, já os nomes repetidos têm um maior conteúdo semântico e são usados anaforicamente quando identificam um antecedente exclusivo (GARROD et al., 1994) ${ }^{6}$.

Segundo os autores acima mencionados, os nomes repetidos - formas mais explícitas - são menos limitados pelo contexto linguístico porque possuem informações semânticas relevantes, independente do sentido da sentença como um todo. Essa característica faz com que uma interpretação anafórica para a solução de nomes repetidos seja menos preferida. Já o pronome, quando encontrado, precisa recuperar, imediatamente, algum elemento linguístico para ser interpretado. Por esse motivo, é mais dependente do contexto do que os nomes repetidos.

Com o texto abaixo, os autores pretenderam observar, através de rastreamento ocular, a influência do foco discursivo, da característica da forma anafórica e da inferência pragmática na resolução de anáforas (GARROD et al., 1994, p. 44):

(A): A dangerous Incident in the pool.

Alexander 1 was an inexperienced swimmer and wouldn't have gone in if the male lifeguard ${ }_{2}$ hadn't been standing by the pool. But as soon as he got out of his depth the started to panic and wave his hands about in a frenzy.

(C1) Within seconds he sank $\boldsymbol{1}_{1}$ into the pool.

(C2) Within seconds he jumped 2 into the pool.

Na passagem C1, a partir da informação contida no verbo sank, há a exclusão do antecedente 2, lifeguard, para a resolução anafórica pronominal. 0 antecedente do pronome é justamente quem está no foco do contexto linguístico anterior (Alexander). Já na sentença C2 fica excluído, a partir da leitura do verbo jumped, o antecedente 1, Alexander. Percebemos que os verbos foram manipulados para influenciar a escolha do possível antecedente. Os leitores interpretavam os antecedentes com base no significado do verbo e do contexto anterior da história explicitada. Nas sentenças experimentais, portanto, a congruência verbal auxiliou a interpretação anafórica pronominal7.

\footnotetext{
${ }^{6}$ Segundo Koch e Elias (2012), o nome repetido é uma forma de progressão referencial denominada de forma nominal reiterada. 0 substantivo Léo na segunda parte da sentença (2), usada como exemplo no presente artigo, é considerado, portanto, um nome repetido. Para Almor (1999), as anáforas podem assumir diferentes formas. Pronomes e nomes próprios são algumas dessas formas. No mesmo artigo o autor chama de anáforas repetitivas aquelas que repetem seu antecedente, assim como de nome próprio repetido (repeated proper name). Chamaremos, no presente trabalho, as retomadas anafóricas com nomes próprios de nome repetido.

${ }^{7}$ Um elemento linguístico inserido num texto é considerado congruente quando seu conteúdo se relaciona harmonicamente com os outros elementos linguísticos formadores do texto do qual fazem parte. A relação
} 
Os resultados encontrados pelos autores mostram que informações de foco, de tipo de expressão anafórica e de inferência pragmática contribuem para o processamento sentencial. Quando o pronome concorda com o foco discursivo, há influência imediata do verbo. Assim, é necessário que ambos, foco discursivo e pronome convirjam para produzir uma influência imediata do verbo na solução anafórica.

Nesse estudo (GARROD et al., 1994), a influência da coerência, manifestada pela congruência verbal, acontece depois que o pronome é encontrado. Para os autores, o conteúdo do pronome pouco contribui para a interpretação geral da sentença em que ele se encontra. Por isso, informações como foco discursivo e inferência pragmática são levadas em consideração tão logo que encontradas.

Como vimos, a manipulação da coerência através dos verbos aconteceu depois que a retomada anafórica foi encontrada. Na presente pesquisa, manipulamos elementos de coesão e a coerência da sentença antes do pronome ou nome repetido para observar se essa manipulação afeta a resolução anafórica diretamente na região onde se encontravam as anáforas com pronome e nome repetido.

Ainda refletindo sobre características de pronomes em função anafórica, temos o trabalho realizado por Arnold et al. (2000). Em experimento utilizando técnica de rastreamento ocular, os autores mostraram aos participantes um desenho e falavam um texto, ao mesmo tempo. Havia, no desenho e no texto, personagens conhecidos dos participantes $^{8}$. 0 texto era composto por quatro partes. $\mathrm{Na}$ primeira, o locutor mencionava os dois personagens. Na segunda, mencionava algum objeto contido no desenho. Na terceira, havia um pronome referindo-se a um dos personagens. A parte final concluía o texto sem mencionar nenhum dos personagens.

Havia, portanto, quatro condições:

a) gêneros diferentes entre primeiro e segundo antecedente e solução anafórica com o primeiro antecedente;

b) gêneros diferentes entre primeiro e segundo antecedente e solução anafórica com o segundo antecedente;

c) gêneros iguais entre primeiro e segundo antecedente e solução anafórica com o primeiro antecedente;

harmônica entre os vários elementos linguísticos que compõem uma sentença leva à compreensão da sentença, concluindo, dessa forma, o processo de obtenção da coerência textual.

${ }^{8}$ No caso desse experimento, os personagens eram: Donald, Mickey e Minnie. 
d) gêneros iguais entre primeiro e segundo antecedente e solução anafórica com o segundo antecedente.

Os participantes identificaram corretamente o personagem antecedente do pronome na maioria das ocorrências nas tarefas de julgamento. Somente quando as duas informações (gênero/acessibilidade) não contribuíam para a resolução pronominal, os leitores encontraram dificuldade em identificar o referente do pronome. Dessa forma, houve uma fixação direcionada ao antecedente pronominal para as três primeiras condições, expostas acima. Na quarta condição, os participantes do experimento fixaram o olhar tanto para o referente quanto para o personagem competidor.

Através desse artigo, Arnold et al. (2000) mostraram que informações de acessibilidade e gênero são acessadas tão logo quando encontrados os pronomes. A acessibilidade está relacionada à posição do antecedente na sentença. Vejamos um exemplo:

(4) Rui conversou com Ivo sobre a prova. Ele tirou uma ótima nota.

Rui é o antecedente mais acessível para a resolução do pronome ele porque aparece primeiro na sentença (4). Já a informação de gênero contida no pronome revela que ambos os antecedentes, Rui e Ivo, são possíveis para a resolução anafórica pronominal.

Os experimentos a serem relatados no presente artigo verificaram se, apesar da existência de antecedente acessível e da informação de gênero, a resolução pronominal foi afetada por incongruências ocorridas na sentença em que ocorre o antecedente das retomadas anafóricas com pronome e nome repetido. Ainda sobre características envolvendo pronomes e nomes repetidos em função anafórica veremos, neste momento, alguns estudos sobre a eficiência de certos tipos de retomadas.

A Teoria da Centralização, formulada por Gordon et al. (1993), afirma que todo enunciado faz referência a uma entidade, chamada de centro anafórico. Essa entidade possibilita interação com o enunciado anterior. 0 pronome exerce, com maior eficiência, essa representação do antecedente porque é um veículo natural para o estabelecimento 
da correferência. A realização de um Backward-looking center ${ }^{9}$ por um nome repetido priva o leitor de pista importante: o conteúdo da sentença atual é coerente com o discurso prévio. Portanto, a utilização de nome repetido no lugar do pronome, em função anafórica, provocaria um prejuízo no processamento denominado de Penalidade do Nome Repetido.

Ainda sobre explicações para o acontecimento da Penalidade do Nome Repetido temos a Hipótese da Carga Informacional. Esta hipótese está relacionada ao princípio de Grice que diz: a contribuição do falante, contida na conversação, será tão informativa quanto for necessária. Assim, os falantes deverão usar formas linguísticas menos complexas e suficientemente informativas. Segundo Almor (1999), o mesmo acontece com as expressões anafóricas. A utilização de determinada forma anafórica terá justificativa no fato de auxiliar na identificação do referente ou adicionar informação sobre o referente ou as duas coisas. É interessante notar que esses aspectos discursivos também estão apoiados na capacidade da memória de trabalho.

A Hipótese da Carga Informacional associa o custo do processamento anafórico à quantidade de informação contida na anáfora. Em experimento, Almor (1999) encontrou penalidade do nome repetido na leitura de nomes repetidos, em função anafórica, fazendo menção a um antecedente em foco, quando comparados ao tempo de leitura de nomes repetidos com antecedente não focalizado. Esse processamento mais custoso se deve, segundo o autor, à utilização não justificada de uma expressão altamente carregada de informação. Segundo Almor (1999), os pronomes têm um menor custo, por sua baixa carga informacional, quando comparados com outra forma anafórica como os nomes repetidos. Assim, a representação menos específica do antecedente tem um menor custo no processamento da retomada anafórica, pois contém menor informação semântica, reduzindo o custo processual da memória de trabalho.

Até agora verificamos estudos psicolinguísticos sobre recursos de coesão referencial com pronomes e nomes repetidos. No presente trabalho, também verificamos a influência de conectivos no processamento anafórico. Vejamos, por isso, o trabalho com conectivos realizado por Sanders e Noordman (2000).

\footnotetext{
9 Backward-looking center é o elemento linguístico que fornece uma ligação coerente com um único forward-looking center (conjunto de elementos que fornecem ligações potenciais com a sentença posterior).
} 
Para investigar as relações de coerência responsáveis pela conexão entre segmentos do texto, Sanders e Noordman (2000) manipularam, nas sentenças experimentais, os tipos de relações de coerência e seus respectivos tipos de conectivos. Vejamos um exemplo de relação de coerência: Claim-argument. Esta acontece quando a segunda oração é um argumento para a afirmação contida na primeira oração (SANDERS; NOORDMAN, 2000, p. 2): It must be a buzzard. It is soaring high in the air.

No exemplo, não há um elemento linguístico conectando explicitamente as duas orações. Esses elementos de conexão poderiam ser because, for, since. Segundo os autores, os conectivos ou marcadores relacionais guiam os leitores na construção representacional do texto, isso porque fornecem informações explícitas sobre as relações entre os segmentos. Em experimento, os participantes leram orações ligadas ou não por conectivos. Os autores perceberam, através de teste sonda, que os participantes julgaram com mais rapidez se uma palavra estava ou não na primeira oração quando as orações eram relacionadas por um conectivo ${ }^{10}$.

A existência de conectivos também proporcionou respostas mais acuradas sobre questões de compreensão. Os resultados sugerem que os conectivos influenciam a representação imediatamente depois de sua leitura. A presença de marcadores linguísticos relacionais facilitou o processamento sentencial pois esses recursos linguísticos, como os conectivos, expressam relações de coerência, guiando o leitor a respeito do sentido do texto. A estrutura de um texto, portanto, ativa expectativas de passagens não lidas. Quando o leitor lê algo referente à descrição de um problema, por exemplo, a expectativa natural da continuidade da leitura é o encontro da solução para tal problema. Da mesma forma, a leitura de marcadores linguísticos instrui o leitor para a seleção da relação de coerência correta, levando-o à compreensão do texto (SANDERS; NOORDMAN, 2000).

A partir das características das anáforas com pronomes e nomes repetidos (maior e menor dependência relacionada ao contexto linguístico; maior ou menor carga informacional; uso imediato de informações de gênero e acessibilidade), assim como da

\footnotetext{
${ }^{10} \mathrm{~A}$ tarefa de reconhecimento de sonda (probe) é capaz de mostrar os efeitos de reativação, ou seja, de recuperação de um item linguístico na memória de trabalho do sujeito participante de um experimento psicolinguístico. Segundo Kenedy (2009), “[...] Nos experimentos com a técnica priming, um estímulo linguístico (ou um conjunto deles) é rapidamente apresentado ao participante e, logo após, uma sonda o induz a dizer se determinada palavra ou sintagma estava ou não presente na frase lida. A maior ou menor dificuldade de recuperação de um item na memória pode ser interpretada com evidência de maior ou menor complexidade no processamento de certos itens linguísticos".
} 
estrutura da sentença da qual fazem parte (papel facilitador dos conectivos e relações de sentido existentes entre esses elementos dispostos em dada estrutura sentencial), podemos pensar quais serão as consequências, em termos de tempo de leitura, da manipulação do contexto linguístico em que estão inseridos os antecedentes dos pronomes e nomes repetidos. Para essa investigação, realizamos dois experimentos que serão relatados adiante ${ }^{11}$.

\section{Experimento 1}

O experimento teve como objetivo investigar a influência da coesão e da coerência no processamento correferencial com base no tempo de leitura de pronomes em posição de sujeito em português brasileiro, a partir da tarefa de leitura automonitorada (self-paced reading).

As variáveis independentes dos experimentos foram ${ }^{12}$ :

a) Coesão (com ou sem item linguístico conectivo) ${ }^{13}$;

b) Coerência (item linguístico congruente ou incongruente).

As variáveis dependentes foram as seguintes: o tempo de leitura do segmento 9 (pronome), do segmento 8 (palavra congruente/incongruente) e segmentos posteriores $(10,11$ e 12). Observamos também o tempo de resposta ao teste sonda (segmento 13). Combinando as duas variáveis independentes em um design $2 \times 2$, em cada conjunto experimental, tivemos as seguintes condições:

a) CSCR (retomada com pronome, com elemento de coesão conectivo e congruente);

b) CSNCR (retomada com pronome, com elemento de coesão conectivo e incongruente);

c) NCSCR (retomada com pronome, sem o elemento de coesão conectivo e congruente);

d) NCSNCR (retomada com pronome, sem elemento de coesão conectivo e incongruente).

\footnotetext{
${ }^{11}$ Certificado de apresentação para a apreciação ética (CAAE): 11859413.2.0000.5188

12 As variáveis de um experimento podem ser independentes ou dependentes. As primeiras se referem aos fatores manipulados pelo criador do experimento. Já a variável dependente é o que se mede com o experimento, ou seja, aquilo que é aferido. 0 pesquisador manipula a variável independente para saber se essa manipulação causa algum tipo de efeito na variável dependente.

${ }^{13}$ Utilizamos os conetivos portanto e por isso.
} 
A partir dessas variáveis temos quatro condições experimentais por experimento:

1) Retomada anafórica de antecedente nominal (CSCR):

Eva/ concluiu/brilhantemente/o texto,/portanto/ o trabalho/ ficou/ primoroso./ Ela/ é/uma excelente /redatora.

2) Retomada anafórica de antecedente nominal (CSNCR):

Eva/ concluiu/brilhantemente/ o texto,/ portanto/ o trabalho/ ficou/ medíocre./ Ela/ é/uma excelente /redatora.

3) Retomada anafórica de antecedente nominal (NCSCR):

Eva/ concluiu/brilhantemente/ o texto,/ o trabalho/ terminado/ ficou/ primoroso./ Ela/ é/uma excelente /redatora.

4) Retomada anafórica de antecedente nominal (NCSNCR):

Eva/ concluiu/ brilhantemente/ o texto,/ o trabalho/ terminado/ ficou/ medíocre./ Ela/ é/uma excelente /redatora.

Foram controlados o tamanho dos nomes próprios, possuindo a mesma quantidade de letras dos pronomes, dessa forma evitamos a influência do fator extensão do constituinte. Também foram controlados o gênero de certos itens lexicais para evitar ambiguidades e a quantidade de nomes e pronomes masculinos e femininos e tipos de conectivos. As sentenças distratoras foram compostas em sua metade por sentenças congruentes e a outra metade por sentenças incongruentes.

\subsection{Método}

\section{Participantes}

Participaram do experimento 21 indivíduos, graduandos da Universidade Federal da Paraíba, todos falantes nativos do português brasileiro, com média de idade de vinte e dois anos.

\section{Material}

O material consistiu, neste experimento, de quatro conjuntos experimentais, com 16 sentenças experimentais. Cada informante foi exposto a um desses conjuntos 
experimentais, embutidos em um conjunto extra de 32 sentenças distratoras. Cada conjunto experimental foi composto por quatro condições, expostas na lista de condições, com quatro sentenças por condição.

No experimento 1, a retomada anafórica de um antecedente nominal é feita por pronome lexical (PR). As sentenças experimentais são estruturadas da seguinte maneira: formadas por período composto na parte em que consta o antecedente e por período simples na parte referente à retomada anafórica.

Cada sujeito foi responsável pela leitura de um conjunto experimental, composto, no total, por 48 sentenças. Através do quadrado latino, todas as condições experimentais foram lidas pelos sujeitos da pesquisa, entretanto, cada conjunto era composto por sentenças referentes a itens experimentais diferentes.

Utilizamos, para a aplicação do experimento, um Macbook Apple (Mac OS X Versão 10.6.3) em conjunto com o programa Psyscope (COHEN et al., 1993), no qual o experimento foi programado e rodado.

\section{Procedimento}

O experimento, elaborado por meio do programa Psyscope, utilizou uma técnica online de leitura automonitorada (self-paced reading) em que os participantes monitoram sua própria leitura em frente à tela do computador e ao teclado, em uma sala isolada no Laboratório de Processamento Linguístico (LAPROL) ${ }^{14}$.

A tarefa consistiu em ler, em velocidade natural, sentenças divididas em doze segmentos, como pudemos observar na lista de condições acima relatadas. Os participantes foram testados individualmente e todos foram primeiramente orientados oralmente pelo experimentador e, depois, por instruções que apareceram na tela do computador.

O início da tarefa consistiu em ler o primeiro segmento e, apertando a letra L do teclado do computador do laboratório utilizado pelo sujeito, outro segmento aparecia

\footnotetext{
${ }^{14}$ O Laprol está localizado em João Pessoa, Paraíba, fazendo parte da Universidade Federal da Paraíba UFPB. Investiga, através de diversas técnicas experimentais (leitura automonitorada, audição automonitorada, priming, julgamento de gramaticalidade controlado, etc.), o processamento da linguagem. As linhas de pesquisa tratam do processamento linguístico em adultos sem patologia, processamento linguístico em aprendizes de L2, e do processamento linguístico em indivíduos com patologias e déficits de linguagem. Além disso, investiga fenômenos referentes à interface Aquisição/Processamento Linguístico. Para maiores informações, visitar a página: http://www.cchla.ufpb.br/laprol/.
} 
para o participante automaticamente. A partir da pressão na tecla L, o próximo segmento aparecia até o término do último segmento (final da frase), sinalizado com um ponto final. Logo em seguida, o participante deveria responder se uma palavra sonda surgida depois de teclar o L para o último segmento - apareceu ou não na sentença que acabara de ler, apertando a tecla SIM ou a tecla NÃO. Com essa pergunta, objetivamos controlar a atenção e a compreensão dos participantes.

Os tempos de todos os 12 segmentos foram gravados e também a opção de resposta (SIM ou NÃO) referente ao teste-sonda. Os sujeitos levaram, em média, 12 minutos para completar a tarefa experimental.

\subsection{Resultados e discussão}

Os resultados do experimento 1, para o segmento 8, estão explicitados na figura $1^{15}$.

Figura 1: Médias dos tempos de leitura do segmento 8, no experimento 1, nas condições envolvendo coesão e coerência

Segmento 8

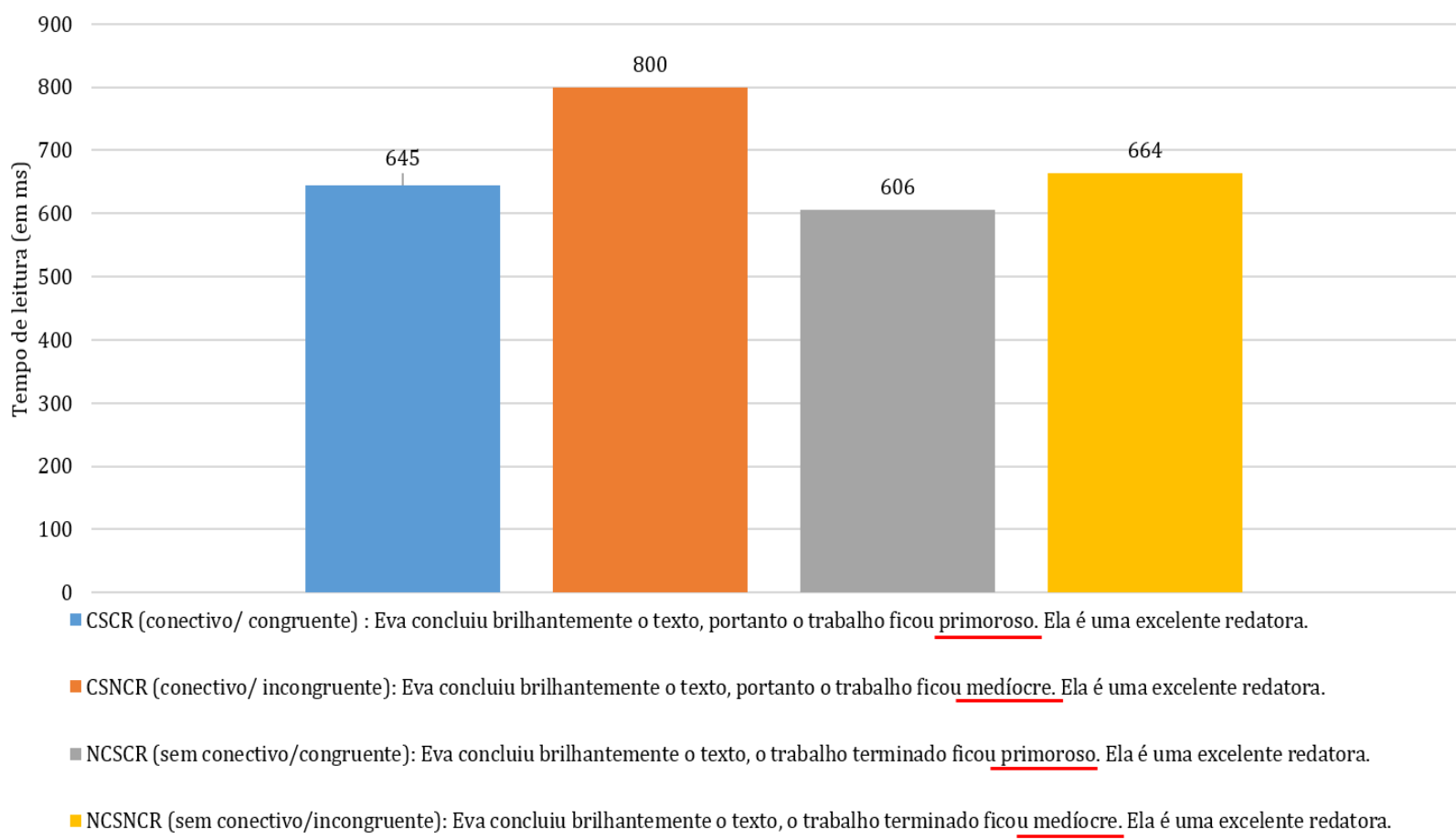

150 segmento 8 está sublinhado na cor vermelha nos exemplos das condições experimentais expostas na figura 1. 
Houve efeito principal de coesão (ANOVA: $F(1,20)=5,76$, p<0,03), de coerência (ANOVA: $F(1,20)=5,84, p<0,02$ ) e de interação entre coesão e coerência (ANOVA: $F(1,20)=4,19, p<0,05)^{16}$.

Quando a sentença é congruente, o tempo de leitura, de maneira geral, é menor (CSCR e NCSCR). Além disso, o efeito de interação entre coesão e coerência, na condição CSNCR, mostra o papel dos conectivos, portanto e por isso, reforçando a expectativa relacionada ao andamento da sentença, causando um maior tempo de leitura quando essa expectativa era quebrada pela leitura do elemento linguístico incongruente contido no segmento 8. Assim, tivemos maiores tempos de leitura para a condição CSNCR quando comparados aos tempos de leitura da condição $\operatorname{CSCR}(\operatorname{t}(20)=2,81, p<0,01)$.

Os elementos sintáticos, nas sentenças experimentais, estão numa ordenação considerada aceitável, porém não expressam uma coerência semântica. Observando os exemplos das condições experimentais CSNCR e NCSNCR, na figura 1, o elemento linguístico medíocre não se relaciona coerentemente com os elementos linguísticos que o antecedem. Podemos notar essa incongruência quando relacionamos os termos medíocre e brilhantemente (localizado no segmento 3) na condição CSNCR: se Eva concluiu brilhantemente o texto, a expectativa era de que o trabalho tivesse ficado primoroso, excelente, perfeito e não medíocre. Há, nesse caso, uma quebra na continuidade harmônica dos elementos linguísticos que compõem o texto. Isso, possivelmente, provocou maiores tempos de leitura nas sentenças incongruentes quando comparadas com as sentenças congruentes.

No segmento 9, referente à retomada anafórica pronominal, não encontramos efeito significativo no tempo de leitura para coesão, ANOVA: $F(1,20)=0,75 ; p<0,39$ e nem de coerência, ANOVA: $F(1,20)=0,002 ; p<0,97$. Também não encontramos efeito significativo de interação, ANOVA: $F(1,20)=0,13 ; p<0,72$ (Figura 2):

\footnotetext{
16 Depois de realizarmos o experimento, os dados encontrados precisaram passar por um pacote estatístico. Para isso utilizamos um programa gratuito chamado ezANOVA que pode ser encontrado na página virtual: http://www.cabiatl.com/mricro/ezanova/ (acesso em 20/02/2014). A análise realizada pelo programa, a partir dos dados obtidos no experimento, culmina com um valor final denominado $\mathrm{p}$ valor. Em Psicolinguística o p-valor, para ser relevante, precisa ser menor do que 0,05 $(p<0,05)$.
} 
Figura 2: Médias dos tempos de leitura do segmento 9, no experimento 1, nas condições envolvendo coesão e coerência

Segmento 9

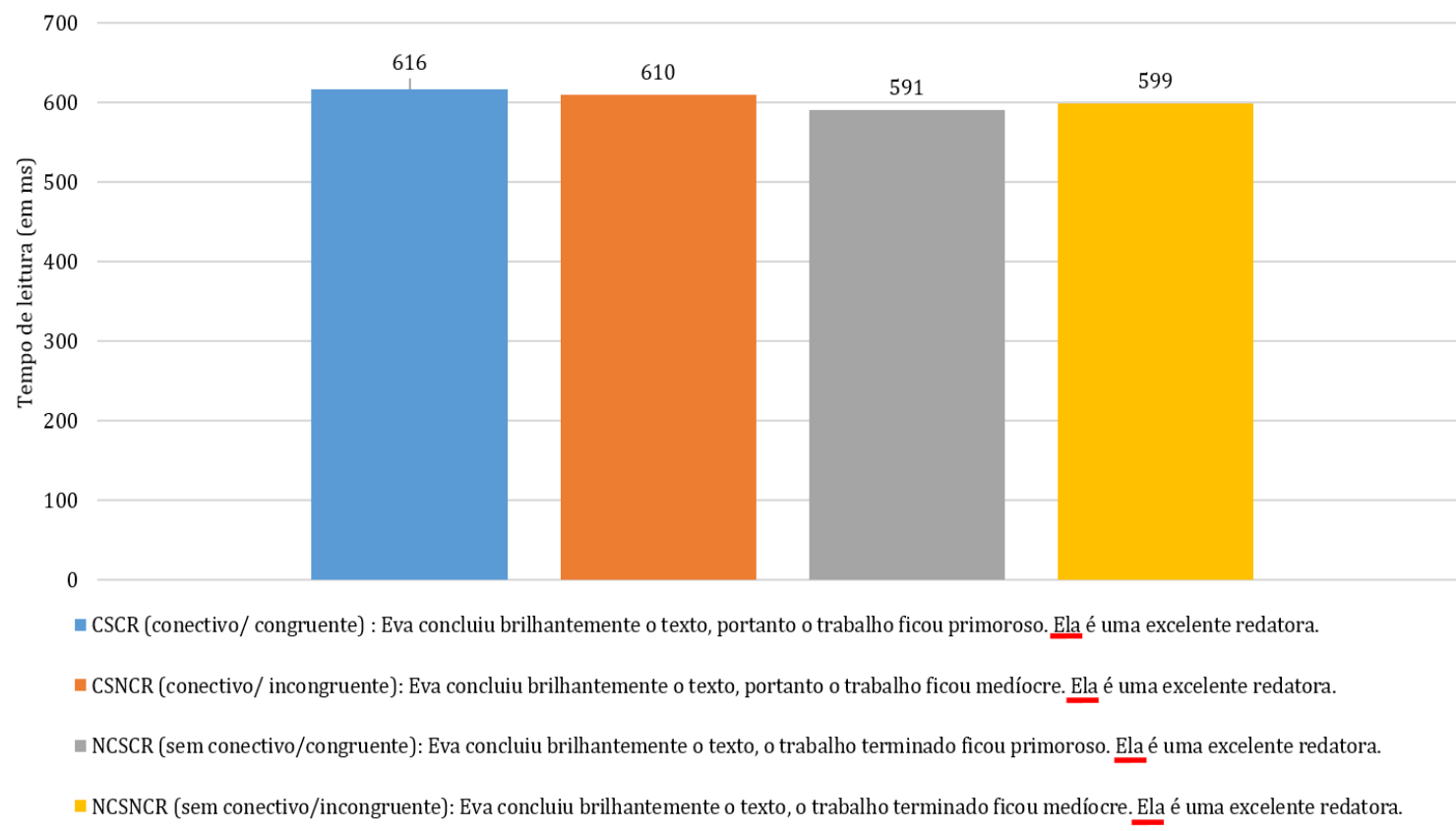

As retomadas com pronome não sofreram qualquer tipo de afetação no tempo de leitura pela existência de incongruência na primeira parte da sentença nas condições CSNCR e NCSNCR. Em experimento utilizando a técnica de rastreamento ocular, Arnold et al. (2000) encontraram uma rápida utilização das informações de gênero e de acessibilidade do antecedente pronominal. Em nosso experimento, o antecedente do pronome, em cada sentença experimental, combinava em gênero e número com o pronome e estava em posição de sujeito. Parece que essas informações foram suficientes para a resolução dos antecedentes dos pronomes nas condições experimentais.

Houve, no teste-sonda, preponderância de respostas afirmativas, com $p<0,001$, no teste de proporção, corroborando o estabelecimento da relação correferencial entre antecedente e retomada ${ }^{17}$. Podemos pensar, portanto, que a correferência foi realizada com sucesso, ainda com a existência de sentenças incongruentes. A tarefa de reconhecimento de sonda (probe) é capaz de mostrar os efeitos da reativação de antecedentes disponíveis, apesar de não ser um monitoramento online do tempo de leitura (LEITÃO, 2005, p. 92). Dessa forma, quando o participante da pesquisa lê o segmento 13 das sentenças experimentais, ou seja, lê elementos linguísticos como Ana,

\footnotetext{
17 Nas sentenças experimentais a palavra-sonda era o antecedente.
} 
Lia, Eva, por exemplo, e aperta a tecla que contém SIM, isso significa que ele achou que leu aqueles elementos linguísticos (Ana, Eva...) anteriormente. Assim, percebemos os sintagmas nominais sendo reativados pelos pronomes ${ }^{18}$.

Não encontramos efeito significativo nos segmentos de número 10, 11 e 12.

Para uma melhor visualização do ocorrido nos segmentos verificados no experimento 1, ou seja, segmentos de número $8,9,10,11$ e 12, observemos a figura 3.

Figura 3: Médias dos tempos de leitura de todos os segmentos das sentenças experimentais do Experimento 1

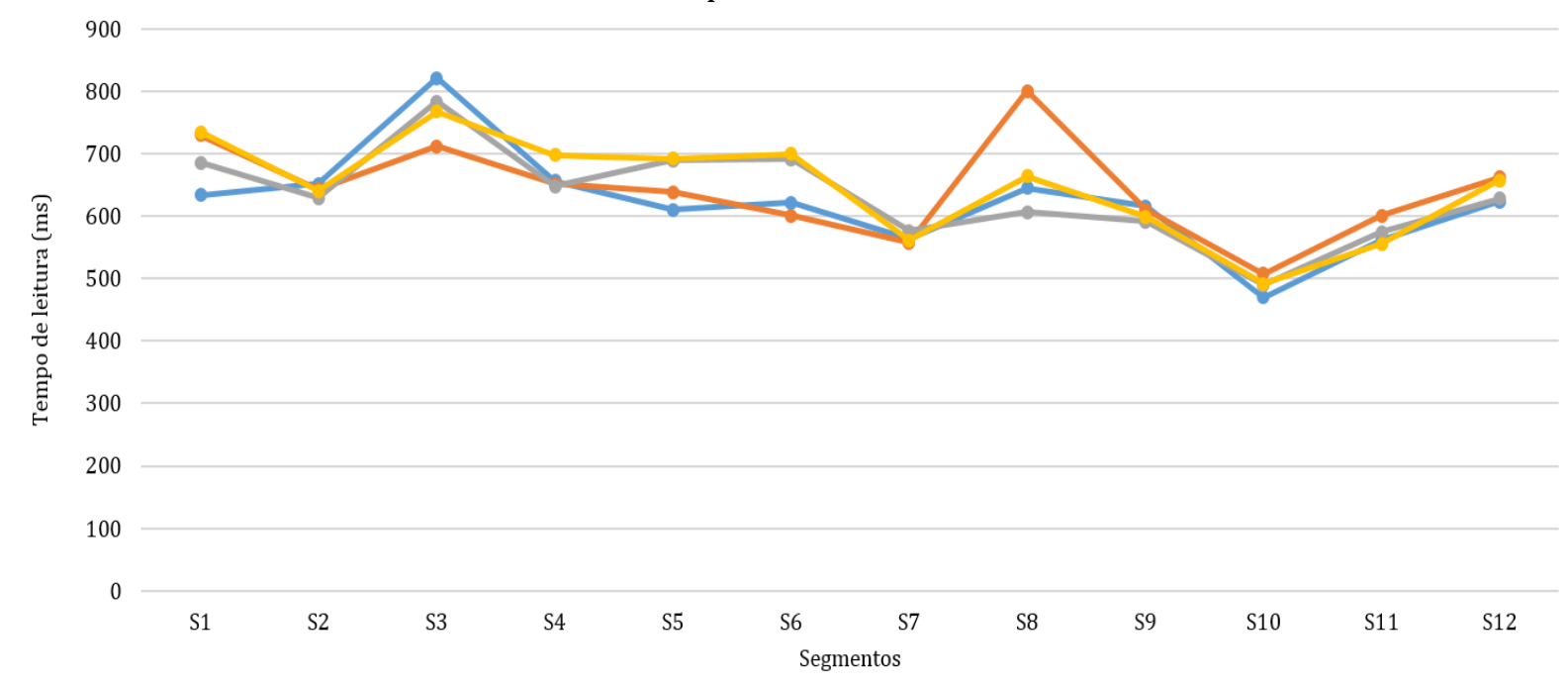

$\leadsto \operatorname{CSCR}$ (Eva/concluiu/brilhantemente/ o texto,/ portanto/ o trabalho/ ficou/ primoroso. /Ela/ é/ uma excelente/ redatora.)

$\sim \operatorname{CSNCR}$ (Eva/ concluiu/ brilhantemente/ o texto,/ portanto/ o trabalho/ ficou/ medíocre./ Ela/ é/ uma excelente/ redatora.)

$\rightarrow$ NCSCR (Eva/ concluiu/ brilhantemente/ o texto,/ o trabalho/ terminado/ ficou/ primoroso./ Ela/ é /uma excelente/ redatora.)

$=$ NCSNCR (Eva/ concluiu/ brilhantemente/ o texto,/ o trabalho/ terminado/ ficou/medíocre./ Ela/ é/ uma excelente/ redatora.)

Percebemos, na figura 3, mais precisamente na parte referente ao segmento 8, os marcadores das condições CSNCR e NCSNCR acima dos marcadores das outras condições (CSCR e NCSCR), assim como visualizamos que os marcadores das condições experimentais não diferem de maneira significativa nos segmentos 9, 10, 11 e 12.

\footnotetext{
${ }_{18}$ As palavras em uma sentença são agrupadas em sintagmas. Estes são formados por um núcleo isoladamente ou com outros elementos dependentes, resultando em uma unidade. Temos, por exemplo, "a menina", como um sintagma nominal formado pelos elementos linguísticos a + menina. As palavras, em um sintagma nominal, estão organizadas em função do núcleo nominal (MAIA, 2006).
} 


\section{Experimento 2}

O experimento teve como objetivo investigar a influência da coesão e da coerência no processamento correferencial com base no tempo de leitura de nomes repetidos em posição de sujeito em português brasileiro, a partir da tarefa de leitura automonitorada (self-paced reading).

O desenho experimental do segundo experimento foi o mesmo do primeiro. A alteração é referente ao tipo de retomada anafórica: neste experimento, utilizamos retomadas com nomes repetidos. Dessa forma, tivemos as mesmas variáveis dependentes e independentes, também contamos com quatro conjuntos experimentais (cada um com 16 sentenças experimentais e 32 distratoras) e realizamos o mesmo procedimento. Utilizamos a mesma máquina para a realização da tarefa pelos sujeitos da pesquisa.

Participaram deste experimento 21 indivíduos, graduandos da Universidade Federal da Paraíba, todos falantes nativos do português brasileiro, com média de idade de dezenove anos. Os sujeitos levaram, em média, 12 minutos para completar a tarefa experimental.

\subsection{Resultados e discussão}

Encontramos efeito significativo de coesão (ANOVA: $F(1,20)=16,8, p<0,001$ ), assim como também encontramos efeito de interação entre coesão e coerência (ANOVA: $F(1,20)=6,41, p<0,02)$ no segmento 8. Os tempos de leitura nas sentenças congruentes foram, em geral, menores do que os das sentenças incongruentes como pudemos observar na figura 4. 
Figura 4: Médias dos tempos de leitura do segmento 8, no experimento 2, nas condições envolvendo coesão e coerência

Segmento 8

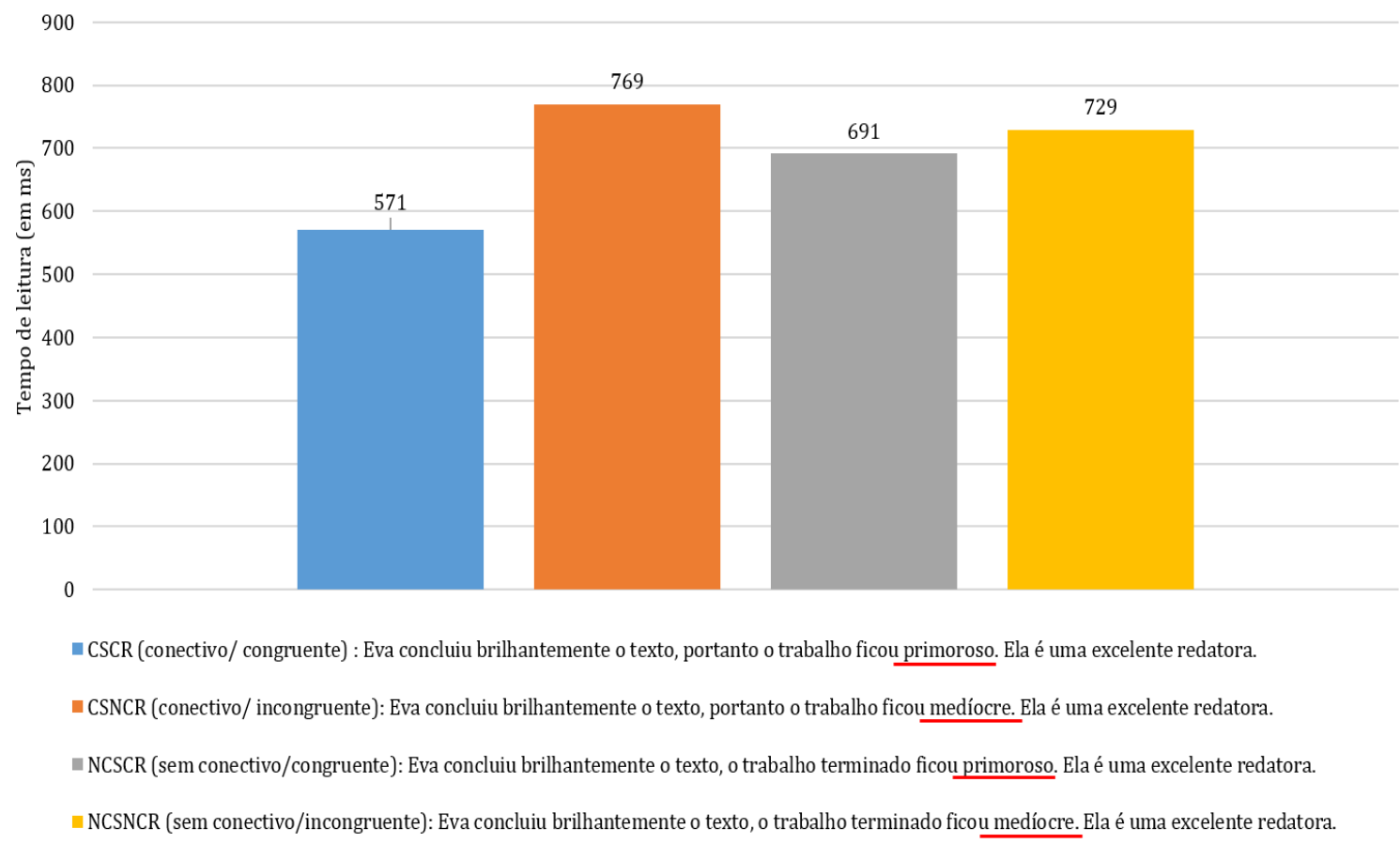

O presente experimento mostrou que a condição CSNCR teve um tempo de leitura significativamente maior do que a condição $\operatorname{CSCR}, t(20)=3,89 ; \mathrm{p}<0,01$. Verificamos, novamente, o papel dos conectivos reforçando a expectativa do leitor sobre o andamento da sentença.

No segmento 9 deste experimento não foram encontradas diferenças significativas entre as condições experimentais, como podemos verificar na figura 5 (coesão, $F(1,20)=0,050$ p<0,82; coerência, $F(1,20)=0,365 p<0,55$; interação, $F(1,20)=$ $2,55 \mathrm{p}<0,12)$ : 
Figura 5: Médias dos tempos de leitura do segmento 9, no experimento 2, nas condições envolvendo coesão e coerência

Segmento 9

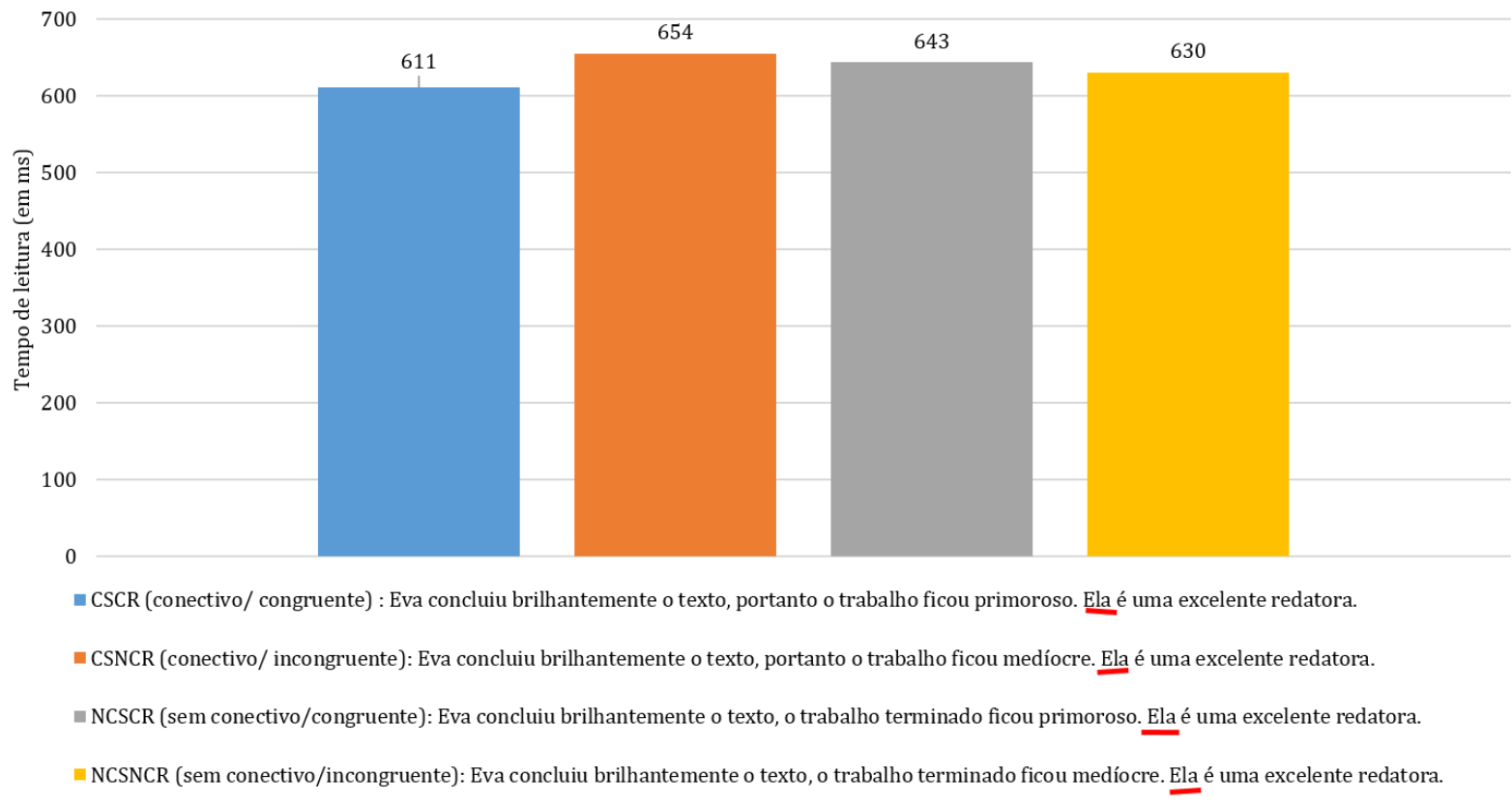

Faz-se necessário reportar o ocorrido no processamento do segmento 10. Este era o segmento imediatamente posterior à retomada anafórica com nome repetido. Encontramos efeito significativo de coesão (ANOVA: $F(1,20)=7,37, p<0,01$ ) e efeito marginal de coerência (ANOVA: $F(1,20)=3,45, p<0,07$ ). Ainda no segmento 10 , quando comparamos sentenças incongruentes (CSNCR e NCSNCS), os maiores tempos de leitura são daquelas portadoras de conectivos $(\mathrm{t}(20)=1,78 ; \mathrm{p}<0,04)$.

No segmento 11 encontramos, no teste-t, menor tempo de leitura para a condição NCSNCR quando comparamos as condições incongruentes: CSNCR e NCSNCR $(t(20)=2,01 ; p<0,05)$. É como se houvesse, aparentemente, um prolongamento do efeito ocorrido no segmento 10. 0 segmento 12 mostrou efeito marginal para coesão (ANOVA: $\mathrm{F}(1,20)=3,68 ; \mathrm{p}<0,06)$.

Vejamos os tempos de leitura de todos os segmentos referentes às condições experimentais - CSCR, CSNCR, NCSCR, NCSNCR - do Experimento 2: 
Figura 6: Médias dos tempos de leitura de todos os segmentos das sentenças experimentais do Experimento 2

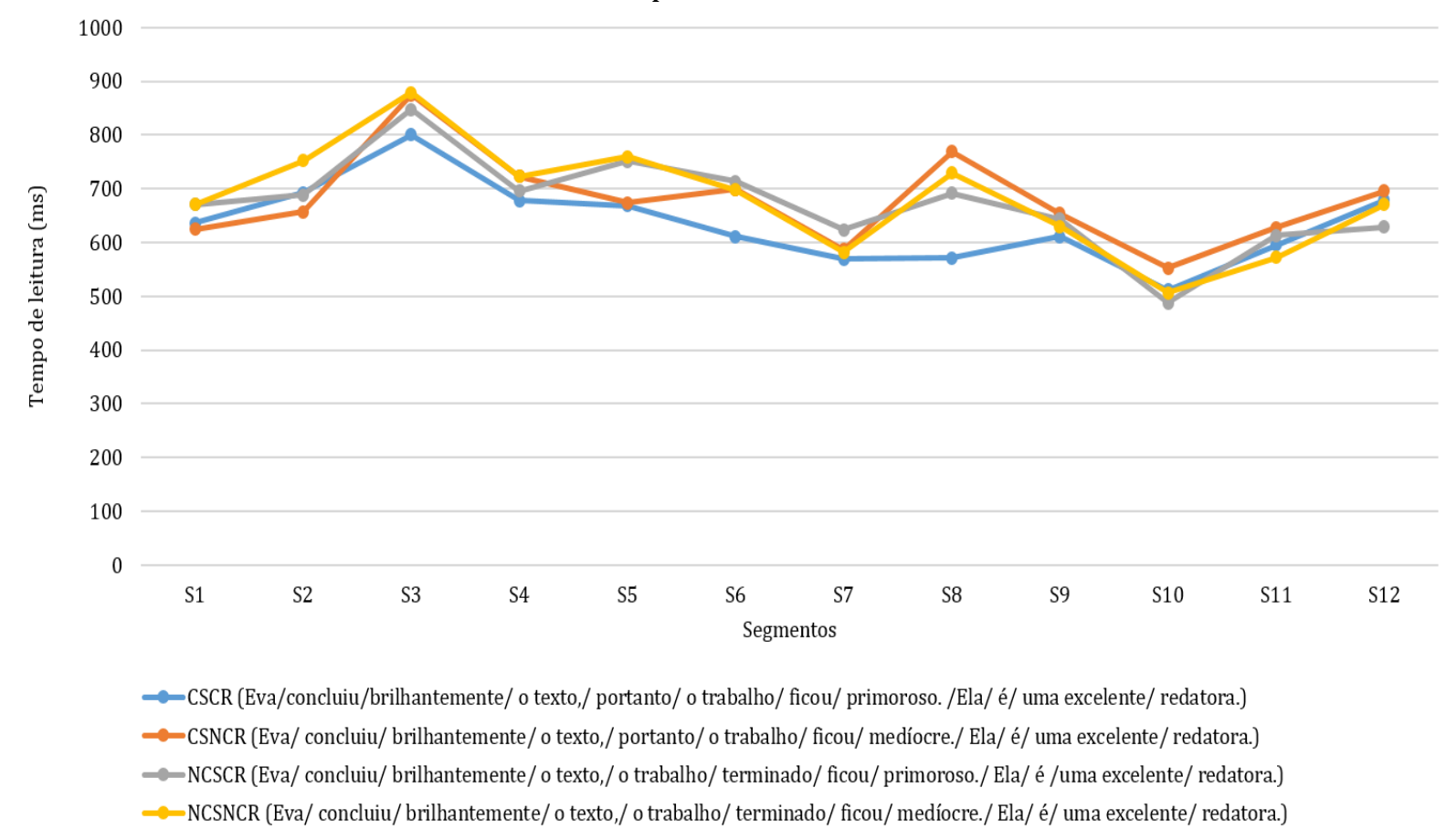

Os sujeitos participantes deste experimento responderam com preponderância afirmativa ao teste-sonda, ( $\mathrm{p}<0,01$, no teste de proporção). Assim como os pronomes, no experimento 1 , os nomes repetidos conseguiram reativar os sintagmas nominais das sentenças do experimento 2.

Percebemos, no Experimento 2, através dos tempos de leitura do segmento 8, o papel dos conectivos reforçando a expectativa sobre o andamento da sentença na condição CSNCR. Quando essa expectativa foi quebrada, encontramos maiores tempos de leitura, no segmento 8, para as sentenças daquela condição experimental.

Também encontramos, de maneira geral, maiores tempos de leitura para as sentenças incongruentes (CSNCR e NCSNCR). 0 processador, portanto, relacionou os elementos linguísticos anteriores ao segmento 8, percebendo a incongruência quando da leitura de elemento linguístico contraditório à totalidade da sentença ${ }^{19}$.

No segmento 9 não houve efeito significativo, mas no segmento 10 encontramos efeito significativo para a coesão e efeito marginal para a coerência. Como podemos explicar tal acontecimento?

\footnotetext{
${ }^{19}$ Segundo Kenedy (2009), o processador ou parser é "[...] o analisador sintático da mente humana".
} 
0 processador percebeu a incongruência contida no segmento 8 da condição CSNCR. No segmento 10 , ou seja, no segmento posterior à retomada anafórica com nome repetido, parece que a combinação do elemento incongruente (arquivado temporariamente na memória de trabalho) mais o nome repetido (anáfora com maior carga informacional e utilizada, na sentença experimental, sem justificativa para esse custo adicional) provocou um maior custo para a memória de trabalho. 0 resultado dessa combinação (incongruência e nome repetido) parece se manifestar, através dos maiores tempos de leitura, no segmento imediatamente posterior à retomada anafórica para as sentenças incongruentes.

Além das implicações da configuração estrutural das sentenças, temos a característica dos nomes repetidos de possuírem informação semântica independente de sua integração com as informações que antecedem esse tipo de retomada. Como vimos anteriormente, essa característica faz com que uma interpretação anafórica para a solução de nomes repetidos seja menos preferida (GARROD et al.,1994). Somemos isso à incongruência de certas condições experimentais e a maior carga informacional dos nomes repetidos e teremos, como resultado, um maior custo processual para memória de trabalho sendo manifestado somente no segmento 10 .

Também é possível refletir sobre uma tendência à penalidade do nome repetido, quando comparamos os tempos de leitura entre os dois experimentos. Nos tempos de leitura do segmento 9 para os experimentos 1 e 2, encontramos um efeito marginal, com $\mathrm{p}<0,06$, quando comparamos o tempo de leitura da condição CSNCR. 0 tempo de leitura para os pronomes nessa condição é menor, se comparados ao tempo de leitura dos nomes repetidos. Isso pode ser devido à maior carga informacional dos nomes repetidos.

No segmento 10 encontramos, significativamente, no teste-t $(\mathrm{p}<0,04)$, menores tempos de leitura no experimento 1, quando comparamos o mesmo segmento com o experimento 2 também na condição CSNCR.

Pelos resultados, comparando os dois experimentos, parece que a combinação da incongruência somada ao nome repetido é mais custosa à memória de trabalho do que a combinação entre incongruência e pronome. A maior carga informacional dos nomes repetidos pode ser um dos fatores que contribuíram para tal resultado. 


\section{Conclusões}

Os resultados obtidos mostraram que tanto no experimento 1 quanto no experimento 2 os sujeitos participantes da pesquisa perceberam a incongruência contida no segmento 8 das sentenças experimentais. Além disso, os conectivos, quando uniam duas orações que manifestavam uma informação incongruente, provocaram um maior tempo de leitura do segmento 8, levando-nos a creditar esse maior tempo de leitura a um maior custo no processamento sentencial.

Os elementos linguísticos contidos numa sentença precisam trabalhar em função da coerência. Nas sentenças incongruentes, apesar da existência de uma ordem lógica, a impossibilidade de relacionar harmonicamente os elementos componentes dessa estrutura bem formada foi percebida pelos sujeitos participantes da pesquisa. A coesão, nessas condições experimentais, não esteve a favor da coerência e os leitores perceberam esse fato, o que resultou em maiores tempos de leitura para as sentenças incongruentes. Entretanto, essa percepção afetou de maneira adversa a computação das anáforas com pronomes e nomes repetidos.

A combinação incongruência e retomada anafórica pronominal, no experimento 1, parece não causar à memória de trabalho algum tipo de efeito considerado mais custoso. Há que se refletir sobre a percepção de elementos incongruentes e sobre a constituição informacional do pronome. Esse tipo de desenho estrutural não causou um processamento mais difícil para a memória de trabalho.

Fato diverso ocorreu em estruturas contendo incongruências e solução anafórica com nomes repetidos. Nesse caso, também é necessária a reflexão sobre a percepção da incongruência e sobre a constituição do nome repetido. Este contém maior carga informacional, além de estar na sentença sem um motivo que justifique o maior custo desse tipo de informação ${ }^{20}$. Ainda, a função anafórica pode não ser a primeira a ser considerada pelo leitor quando do encontro de um nome repetido. Esses fatores,

\footnotetext{
${ }^{20}$ Nas sentenças experimentais, o nome repetido não adiciona informação e não auxilia na identificação do antecedente. Poderíamos refletir sobre um auxílio na resolução anafórica se a distância que separa retomada com nome repetido de seu antecedente fosse substancial, o que não foi o caso das sentenças utilizadas nos experimentos. Ainda assim, Leitão e Simões (2011) encontraram maiores tempos de leitura para nomes repetidos, quando comparados aos pronomes, em função anafórica, mesmo em maiores distâncias separando antecedente da retomada anafórica, o que corrobora a Penalidade do Nome Repetido.
} 
combinados, pareceram mais custosos ao processador. Podemos pensar que a memória de trabalho teve mais informações a serem processadas e armazenadas, principalmente quando comparamos à estrutura contendo a solução anafórica pronominal.

Os resultados obtidos nos experimentos 1 e 2 possibilitaram a reflexão sobre pesquisas futuras verificando a influência do vínculo sintático no processamento anafórico a partir de sentenças experimentais incongruentes como:

(5) Eva/ concluiu/brilhantemente/o texto,/ portanto/ o trabalho/ ficou/ medíocre/ e/ ela/ é/ uma excelente/ redatora.

Em pesquisa futura, observaremos se o fato de a incongruência ter acontecido e terminado com o ponto final no segmento 8 dos experimentos 1 e 2 fez com que o leitor não levasse adiante a quebra da expectativa para a segunda parte da sentença, iniciada com pronome. Verificaremos se a continuidade da sentença depois de uma palavra incongruente pode provocar algum efeito no momento da leitura da anáfora. 0 vínculo entre a retomada com a oração onde se localiza a incongruência provocará resultados diferentes dos encontrados no experimento 1 ?

O vínculo sintático pode proporcionar condições de acesso a sintagmas nominais alternativos (CORRÊA, 1998) durante a interpretação pronominal. A partir dessa afirmação, poderemos perceber se a resolução anafórica pronominal será afetada por incongruências na sentença que antecede o pronome quando há vínculo sintático entre incongruência e anáfora pronominal. Investigaremos, portanto, se diferentes configurações sintáticas suscitarão consequências diversas no processamento sentencial.

A influência da constituição sintática e semântica na resolução anafórica foi observada através do tempo de leitura dos sujeitos participantes dos experimentos realizados. Entretanto, os resultados provocaram a necessidade de investigações posteriores a respeito do processamento anafórico. Ainda assim, esperamos que os resultados obtidos e análises empreendidas tenham fornecido material relevante à compreensão do processamento correferencial, contribuindo para o que se já conhece a respeito do fenômeno e para fomentar as vindouras pesquisas concernentes à linguagem humana. 


\section{Referências}

ALMOR, Almor. Noun-phrase anaphora and focus: the informational load hypothesis. Psychological Review, v. 106, n. 4, p. 748-765, out. 1999.

ARNOLD, Jennifer E.; EISENBAND, Janet; BROWN-SCHMID, Sarah; TRUESWELL, John C. The rapid use of gender information: evidence of the time course of pronoun resolution from eyetracking. Cognition, v. 76, p. B13-B26, 2000.

CANÇADO, Márcia. Manual de Semântica: noções básicas e exercícios. São Paulo: Contexto, 2012.

COHEN, Jonathan D.; MacWHINNEY, Brian; FLATT, Matthew; PROVOST, Jefferson. Psyscope: a new graphic interactive enviroment for designing psychology experiments. Behavioral Research Methods, Instruments \& Computers, v. 25, n. 2, p. 257-271, 1993.

CORRÊA, Letícia Maria Sicuro. Acessibilidade e paralelismo na interpretação do pronome sujeito e o contraste pro/pronome em português. Delta, v. 14, n. 2, 1998.

FÁVERO, Leonor Lopes; KOCH, Ingedore Grunfeld Villaça. Linguística textual: introdução. São Paulo: Cortez, 2012.

GARROD, Simon; FREUDENTAL, Daniel; BOYLE, Elisabeth. The role of different types of anaphor in the online resolution of sentences in a discourse. Journal of Memory and Language, v. 33, p. 39-68. 1994.

GORDON, Peter C.; GROSZ, Barbara J.; GILLION, Laura A. Pronouns, names, and the centering of attention in discourse. Cognitive Science. v. 17, p. 311-347, 1993.

HASAN, Ruqaiya; HALLIDAY, M.A.K. Cohesion in English. Londres: Longman, 1976.

KENEDY, Eduardo. Gêneros textuais e psicolinguística: caminhos para um diálogo. [s.d]. Disponível em: http://www.professores.uff.br/eduardo/artigos arquivos/generos textuais 2009.pdf Acesso em 31 jul. 2013.

KOCH, Ingedore Grunfeld Villaça. A coesão Textual. São Paulo: Contexto, 1994.

KOCH, Ingedore Grunfeld Villaça; ELIAS, Vanda Maria. Ler e compreender: os sentidos do texto. São Paulo: Contexto, 2012.

KOCH, Ingedore Grunfeld Villaça; TRAVAGLIA, Luiz Carlos. Texto e coerência. São Paulo: Cortez, 2007.

LEITÃO, Márcio M.; SIMÕES, Antonia B. G. A influência da distância no processamento correferencial de pronomes e nomes repetidos em português brasileiro. Veredas on-line, v. 1, p. 262-272, 2011. 
LEITÃo, Márcio M. Processamento do objeto direto anafórico. 2005. 149 fls. Tese (Doutorado em Linguística). Universidade Federal do Rio de Janeiro, Rio de Janeiro, 2005.

MAIA, Marcus. [s.d] Manual de Linguística: subsídios para a formação de professores indígenas na área da linguagem. Disponível em: http://portal.mec.gov.br/index.php? option=com docman\&task=doc download\&gid=646\&Itemid Acesso em 01 mar. 2014.

SANDERS, Ted J. M.; NOORDMAN, Leo G.M. The role of coherence relations and their linguistic markers in text processing. Discourse Processes, v. 1, 2000.

Recebido em março de 2014.

Aceito em junho de 2014. 